\title{
A RELEVÂNCIA DO DESIGN UNIVERSAL PARA O DESENVOLVIMENTO DE PRODU- TOS \\ Um estudo de caso das fruteiras de supermercados de Maceió - AL
}

Thays da Costa Oliveira

Débora Clarissa Ferreira de Pontes

Maria Eduarda Ramos Cavalcanti Rosa

\begin{abstract}
Resumo: A ergonomia pode ser definida como a adaptação da atividade ao homem, onde diversos fatores se relacionam a esse estudo, sendo alguns deles: a máquina, o ambiente, a informação, organização e as consequências da integração entre o produto e usuário. 0 design se utiliza dos conhecimentos e conceitos da ergonomia de modo a potencializar o diagnóstico das pesquisas e posterior aplicação na solução do problema. Uma das ferramentas utilizadas para isso é o estudo da análise da tarefa e da antropometria. O presente artigo centraliza-se nos aspectos antropométricos aplicados às fruteiras de supermercados da cidade de Maceió - AL, sob a forma de padrões referenciais do Design Universal.
\end{abstract}

Palavras-chave: design universal, ergonomia, fruteiras, mercados, Maceió-AL

\section{INTRODUÇÃO}

A fruta (ou fruto) é um produto comestível obtido a partir de plantas cultivadas ou silvestres. Apresenta alta porcentagem de água (podendo chegar aos 95\%) e é rica em vitaminas e minerais, além de fibras, sendo por isso indicada ao consumo humano como modo de auxílio para a saúde e qualidade de vida (LIU, 2006). Normalmente são consumidas em estado maduro e para melhor apreciação da sua qualidade, elas devem ser extraídas e armazenadas da maneira correta, sendo influenciada pelas características climáticas das suas respectivas regiões de cultivo, além da correta conservação após a colheita (SUDHEER, 2007).

Para que essas cheguem às nossas casas passam pelo processo de plantio, colheita, seleção, empacotamento e transporte, sendo condicionantes do transporte (a exemplo da trepidação e empilhamento) fatores que podem influenciar no produto final. Sendo assim, as embalagens são bastante importantes e tem ganhado cada vez mais atenção dos produtores e consumidores. Entretanto, nem todas as frutas são embaladas antes de chegarem ao consumidor. Muitas delas precisam ser escolhidas e essa não se dá apenas pelo aspecto visual, mas também pelo tato e o olfato. Corroborando com isso, Gutierrez (2005) diz que a comercialização das frutas é dependente da apreciação positiva do consumidor, que está relacionada principalmente com a aparência e as características sensoriais, além da garantia de segurança e qualidade, possibilitando ao estabelecimento estratégias diferenciadas de comercialização.

A tarefa de escolher as frutas nos supermercados e feiras podem ser otimizadas com

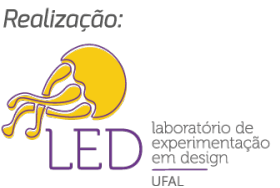


o auxílio da setorização dessas em fruteiras de acordo com as características climáticas que cada tipo demanda. Como a atividade de ir ao supermercado é comum à maioria da população e a aquisição de mobiliários e objetos para disposição dos produtos facilita no processo de escolha pelo consumidor, percebeu-se a pertinência de introduzir o estudo ergonômico para perceber as dificuldades de diferentes pessoas na tarefa de comprar alimentos, a fim de estabelecer a relação entre a criação de novos produtos e o Design Universal. Segundo Bifano (2000), entende-se por Design Universal um processo de concepção de produtos às necessidades da maioria das pessoas, otimizando a sua usabilidade. São incluídos todos os gêneros, raças, idades, classes sociais, tamanhos, bem como pessoas com deficiências e limitações.

Percebendo que o a ergonomia aplicada ao desenvolvimento de produtos pode colaborar para melhoria efetiva dos serviços prestados, este artigo procura levantar e discutir algumas reflexões acerca do tema. Com base em dados antropométricos da literatura e pesquisa de campo (com a utilização de princípios metodológicos da análise ergonômica do trabalho), foram analisados aspectos ligados à eficiência e adequação das normas vigentes à satisfação da população ao usar fruteiras.

\section{DESENVOLVIMENTO}

\subsection{A ergonomia e o Design Universal para o desenvolvimento de produtos}

Segundo BAXTER (1998), para que possa se atingir um alto nível de competitividade, o desenvolvimento de produtos deve ser bem elaborado em sua concepção, de modo a se diferenciar dos existentes no mercado. Entretanto, segundo Ribeiro (2001), para se criar um produto diferenciado é preciso se considerar os usuários. O Design Universal surge como uma estratégia de mercado nos tempos contemporâneos, onde a inclusão é muito pertinente.

São tidos como princípios do Design Universal descritos por Carletto et. al. (2008) e Trani (2010) os seguintes quesitos:

a) Igualitário (que podem ser utilizados por pessoas com diferentes capacidades, evitando a segregação e oferecendo privacidade e segurança aos usuários);

b) Adaptável (às necessidades de diferentes usuários, admitindo adequações e transformações);

c) Intuitivo (de fácil entendimento, eliminando complexidades desnecessárias e ser coerente com as expectativas e intuição do usuário);

d) Informação de fácil percepção (as informações devem ser transmitidas de forma a atender as necessidades do receptador e as suas limitações de visão ou audição);

e) Tolerância ao erro (minimizar os riscos e possíveis consequências de ações acidentais);

f) Esforço físico mínimo (projetados para uso eficiente, com conforto e com o mínimo de fadiga, minimizando ações repetitivas e esforços físicos);

g) Dimensionamento de espaços para acesso e uso abrangente (dimensões e espaços devem ser apropriados ao acesso, alcance, manipulação e o uso da maioria das pessoas).

Percebe-se através dos princípios do Design Universal, que ele se utiliza dos conhecimentos da ergonomia para propor o desenvolvimento de soluções centradas na melhor interação entre o produto-usuário. Segundo Adul et. al., os estudos ergonômicos 
contribuem na solução de problemas de usabilidade, tornando os produtos mais adequados à saúde, segurança, conforto e eficiência e minimizando os erros (ADUL et. al., 2004). Consonante, a ABERGO - Associação Brasileira de Ergonomia (2000), diz que a ergonomia objetiva modificar os sistemas de trabalho para adequar as atividades existentes às características, habilidades e limitações das pessoas, tendo em vista o seu desempenho. Sendo, entretanto, para a realização de um produto coerente com a realidade e necessidades específicas dos usuários, importante a utilização da ergonomia física e cognitiva em conjunto.

Segundo lida (2005), a ergonomia física trata da relação das características anatômicas, antropométricas, fisiológicas e biomecânicas do homem com a atividade física realizada; enquanto que a ergonomia cognitiva compreende processos mentais nas interações do homem com os elementos de um sistema e/ou produto. Para Vidal (2002), a ação ergonômica consiste numa articulação e atuação técnica. O autor define a intervenção ergonômica como sendo a produção de um conjunto específico de respostas às demandas, onde estas estariam pautadas sobre o trabalho realizado e o projeto adequado de produtos.

Dentre as áreas de conhecimento mais abordadas pela ergonomia no desenvolvimento de novos produtos, está o estudo da antropometria - compreendida como a ciência que trata das medidas físicas do corpo humano (PANERO, 2002). No desenvolvimento de produtos e adaptações desses ao design, a antropometria é essencial, pois é através dela que se tem o conhecimento das dimensões físicas do homem levando em consideração seu sexo, faixa etária e tipo físico. Alguns condicionantes, entretanto, são muito importantes para o emprego de maneira satisfatória da antropometria, dentre esses estão: cultura, classe social, escolaridade, além do diagnóstico dos problemas encontrados pelo público alvo durante a atividade realizada, sendo esse fator identificado através da análise da tarefa.

\subsection{Metodologia}

O método utilizado envolveu pesquisa in loco com diferentes tipos físicos, a fim de avaliar as dificuldades dos usuários ao utilizar fruteiras dos supermercados na cidade de Maceió - AL.

As análises do público alvo e dos similares foram baseadas em Gui Bonsiepe (1984), que diz que para a criação de um produto é imprescindível que a síntese e diagnóstico do problema sejam bem estruturados, fracionados e hierarquizados de acordo com os níveis de importância do projeto.

Para isso, diante da perspectiva do Design Universal, o estudo da ergonomia é bastante pertinente, onde foi adotada a análise dos processos de trabalho propostos por Vidal (2002), levando-se em consideração os dados antropométricos de Panero (2002). Na pesquisa foram analisadas as pegas e manejos, posturas e antropometria, para alcançar possíveis diretrizes de adequação do projeto aos usuários.

\subsection{Resultados e Discussão}

\subsubsection{Análise da Tarefa}

A fim de verificar a eficácia das fruteiras existentes nos supermercados da cidade de Maceió, foram realizadas visitas a alguns estabelecimentos para observação do público e suas possíveis dificuldades ao executar as atividades. Ao analisar as fruteiras existentes nos supermercados quanto aos princípios do Design Universal, foram encontrados alguns problemas. Dentre os principais: 
1- Altura excessiva da disposição das frutas;

2- Fluxo ruim no ambiente no qual a fruteira está inserida;

3- Barreiras que impedem a aproximação do usuário;

4- Disposição desorganizada das frutas;

5- Falta de espaço para manobra de cadeira de rodas;

6- Ausência de informações acessíveis a deficientes visuais.

Após esse diagnóstico preliminar, foi feito um questionário com o público através de entrevistas e conversas presenciais, onde foram apontadas duas predileções para as fruteiras (Figura 1 e 2), sendo essas analisadas de maneira mais aprofundada em relação as suas medidas (Quadro 1), a fim de se perceber posterirormente as possibilidades de adequação as medidas antropométricas.

Figuras 1 e 2 - Fruteiras do supermercado Unicompras Maceió - AL. Fonte: Elaborado pelo autor, 2017.
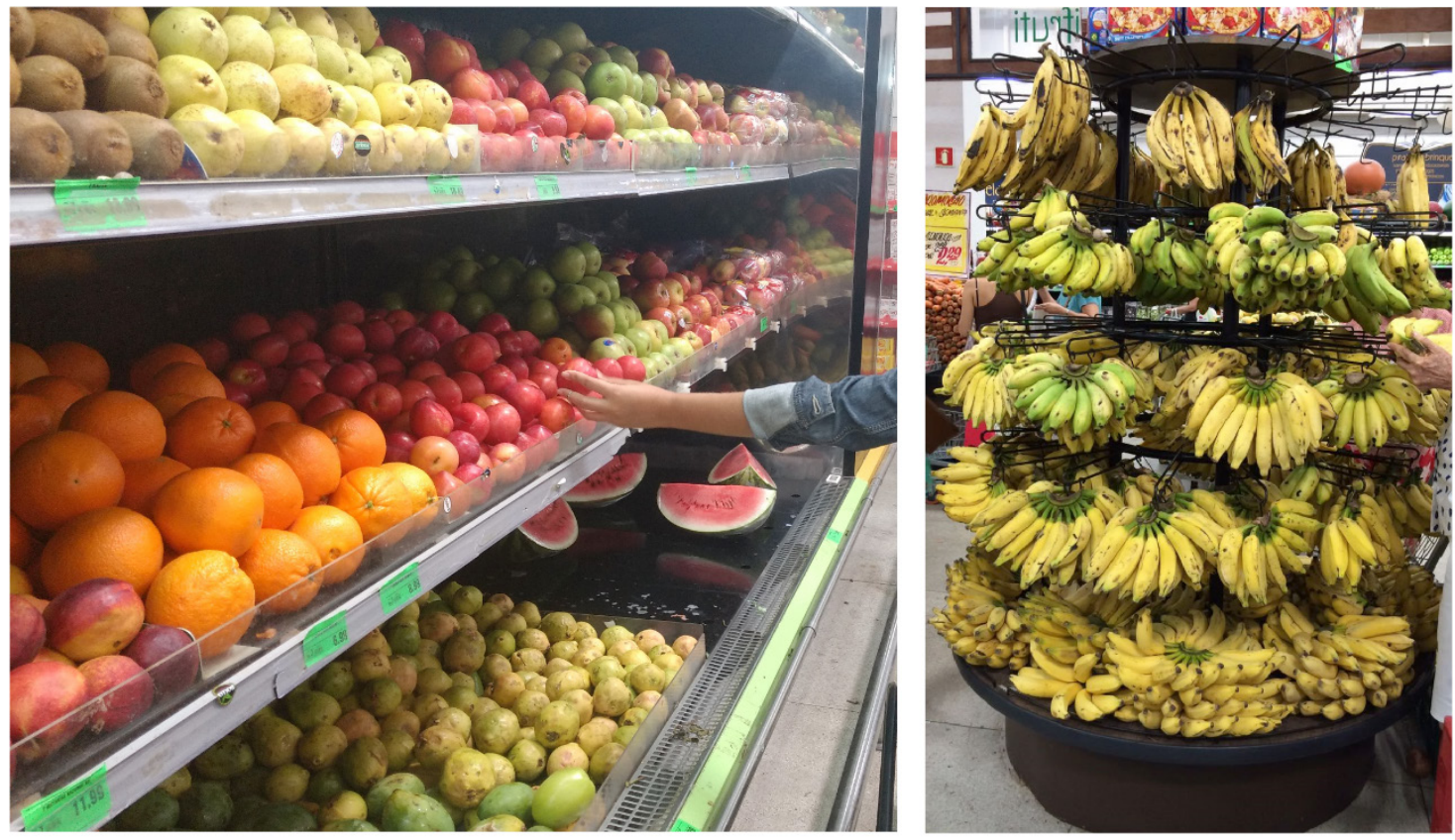

Quadro 1: Medidas da fruteiras analisadas. Elaborado pelo autor, 2017.

\begin{tabular}{|l|c|c|}
\cline { 2 - 3 } \multicolumn{1}{c|}{} & Fruteira 1 & Fruteira 2 \\
\hline Largura total/Diâmetro & $1000 \mathrm{~cm}$ & $135 \mathrm{~cm}$ \\
\hline Altura total & $210 \mathrm{~cm}$ & $180 \mathrm{~cm}$ \\
\hline Altura da barra de proteção & $20 \mathrm{~cm}$ & - \\
\hline Altura da base & $40 \mathrm{~cm}$ & $40 \mathrm{~cm}$ \\
\hline Espaço entre uma prateleira e outra & $43 \mathrm{~cm}$ & $38 \mathrm{~cm}$ \\
\hline Profundidade das prateleiras/ganchos & $54 \mathrm{~cm}$ & $13 \mathrm{~cm}$ \\
\hline Espaço de fluxo frontal/Lateral & $120 \mathrm{~cm}$ & $68 \mathrm{~cm}$ \\
\hline
\end{tabular}

A análise da tarefa foi realizada de modo a registrar as ações do usuário e identificar problemas da utilização dessas fruteiras. De acordo com as observações feitas nos estabelecimentos, foram identificadas duas situações principais sobre a tarefa a ser realizada: na primeira, a utilização da fruteira por pessoas sem necessidades especiais e na segunda a utilização de fruteiras por pessoas com necessidades especiais. Em ambas as situações as tarefas passam pelas seguintes micro tarefas sequenciais: 
1. Posicionar-se;

2. Avançar o braço verticalmente ou horizontalmente;

3. Segurar a sacola com uma das mãos;

4. Pegar a fruta;

5. Analisar se a fruta está boa.

Figura 3 - Tarefas realizadas por pessoas sem deficiências físicas. Fonte: Elaborado pelo autor, 2017.
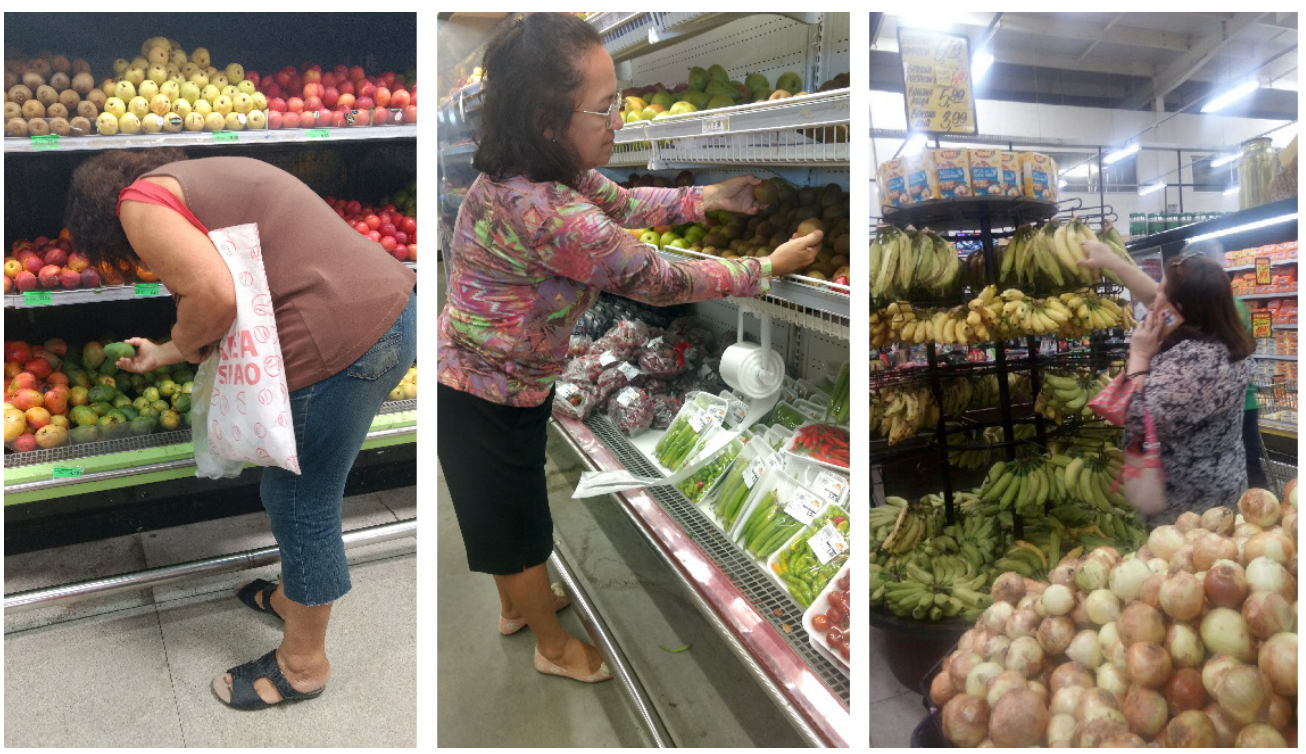

Ao analisar as tarefas das pessoas sem necessidades especiais (Figura 3), percebeuse que ao avançar o braço, a postura do usuário esteve condicionada as características formais da fruteira e a altura das prateleiras. Quando a prateleira estava entre a altura dos quadris até os ombros do usuário, foi realizado o movimento de curva-se para frente a fim de alcançar a fruta e escolhe-la. Dependendo da altura do usuário e a constância do exercício, existe uma tensão na coluna cervical.

Quando as prateleiras são mais baixas que a altura do quadril, o usuário necessita agachar-se para fazer a escolha da fruta ou aumenta o ângulo de curvatura da cervical, causando fadiga. Quando as prateleiras são mais altas que o público, houve necessidade de esticar os braços e o corpo para conseguir realizar o alcance. Para esse pode ser exercido o movimento de supinação, quando do levantamento do ombro para esticar o braço, e também será exercido o movimento de pronação com o antebraço para pegar as frutas e recolher a mão. Esse movimento por sua vez, causa fadiga quanto à postura aos ombros e braços. A Figura 4 mostra as posturas inadequadas que podem ocorrer em virtude dessas situações. 
Figura 4 - Posturas adequadas e inadequadas nas tarefas. Fonte: PANERO (2002), adaptada pelo autor, 2017.

\section{POSTURAS INCORRETAS}
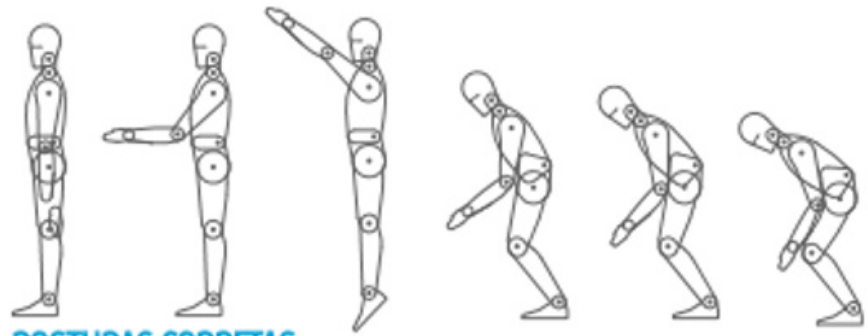

POSTURAS CORRETAS
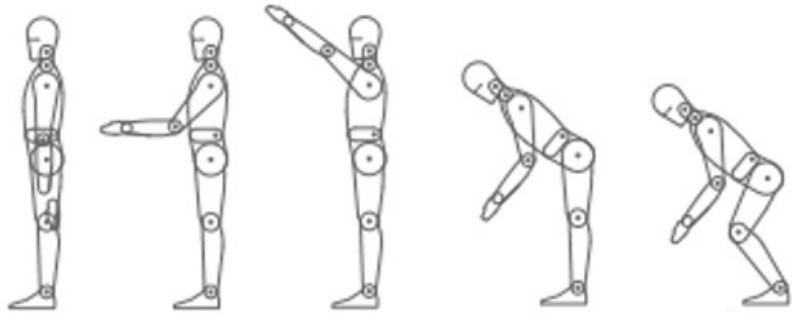

A depender do recuo das prateleiras e dos possíveis obstáculos (no acaso da Fruteira 1, com a barra de proteção), os usuários não conseguem segurar com precisão as frutas, podendo deixa-las cair, o que resulta no comprometimento da qualidade da mesma para o consumo. Além disso, percebe-se que a falta de inclinação faz com que o usuário alcance apenas as frutas que estão na frente. Outro ponto importante de dificuldade é a barra de proteção que não permite a pessoa de se aproximar, aumentando a dificuldade de visualização de informações sobre a fruta - como nome, tipo e preço - que por sua vez tem tamanho muito reduzido (Figura 5). Para os portadores de necessidades especiais, o quesito visualização das informações fica ainda mais crítico.

Figura 5 - Informação sobre a fruta em tamanho muito reduzido. Fonte: Elaborado pelo autor, 2017.

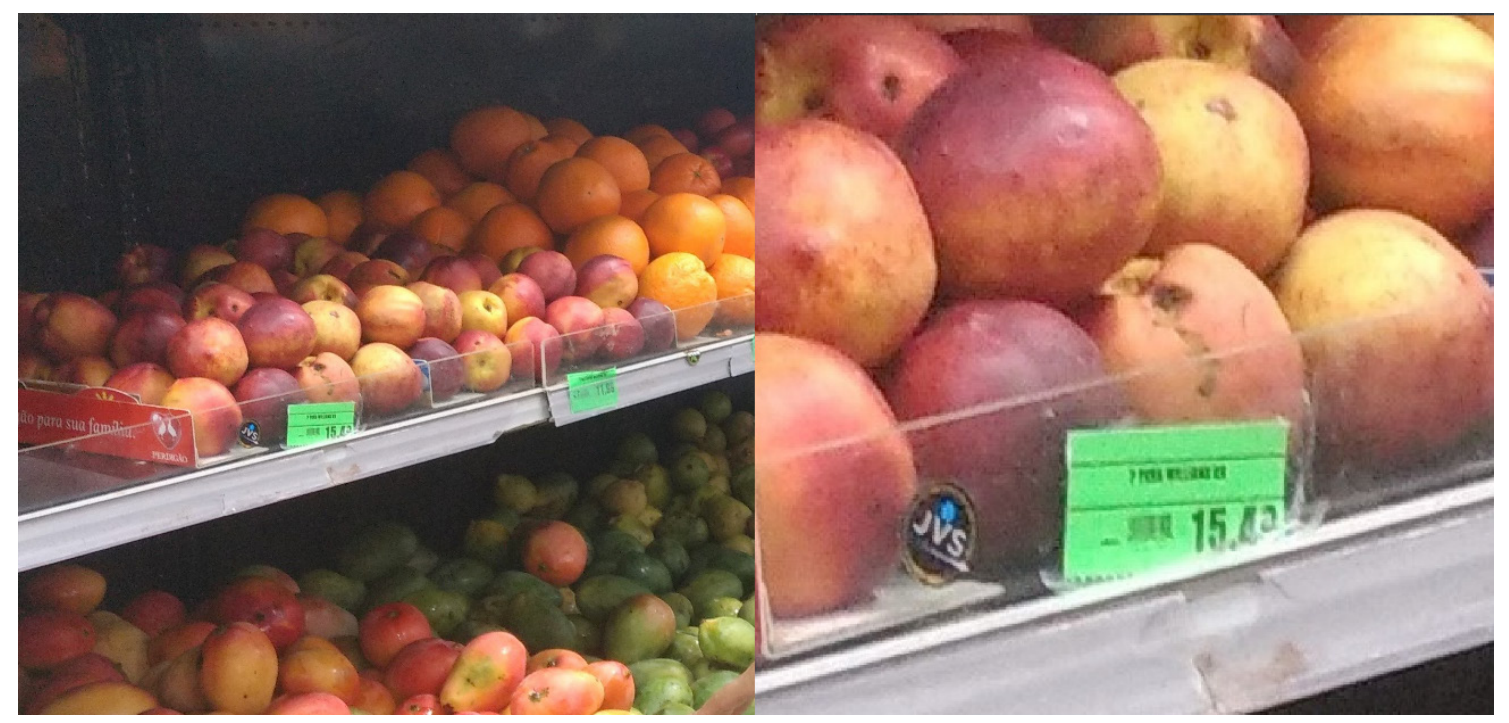

Ao analisar as tarefas das pessoas com necessidades especiais, foram considerados cadeirantes; pessoas com baixa mobilidade e deficientes visuais ou com baixa visibilidade. Percebeu-se que todos tiveram dificuldades de aproximação na Fruteira 1 devido ao obstáculo da barra de proteção de aço, e pela obstrução de mobiliários na passagem para manobra (no caso dos cadeirantes).

Os cadeirantes (Figura 6) também sentem dificuldade no alcance da fruta de maneira frontal, onde muitas vezes precisam posicionar a cadeira na lateral da fruteira para pegar 
a fruta de maneira lateral (Figura 7), exercendo o movimento de supinação com o ombro, levantando-o para esticar seu braço, bem como realizando o movimento de pronação com seu antebraço para pegar as frutas. Como há o problema referente à má distribuição das frutas em alturas variadas, o usuário é obrigado a se curvar ou se esticar, para frente ou para os lados, para alcançar e escolher as frutas. Para os deficientes físicos essa atividade se torna muito mais complexa.

Figura 6 - Tarefas realizadas por pessoas com deficiências físicas. Fonte: Elaborado pelo autor, 2017.
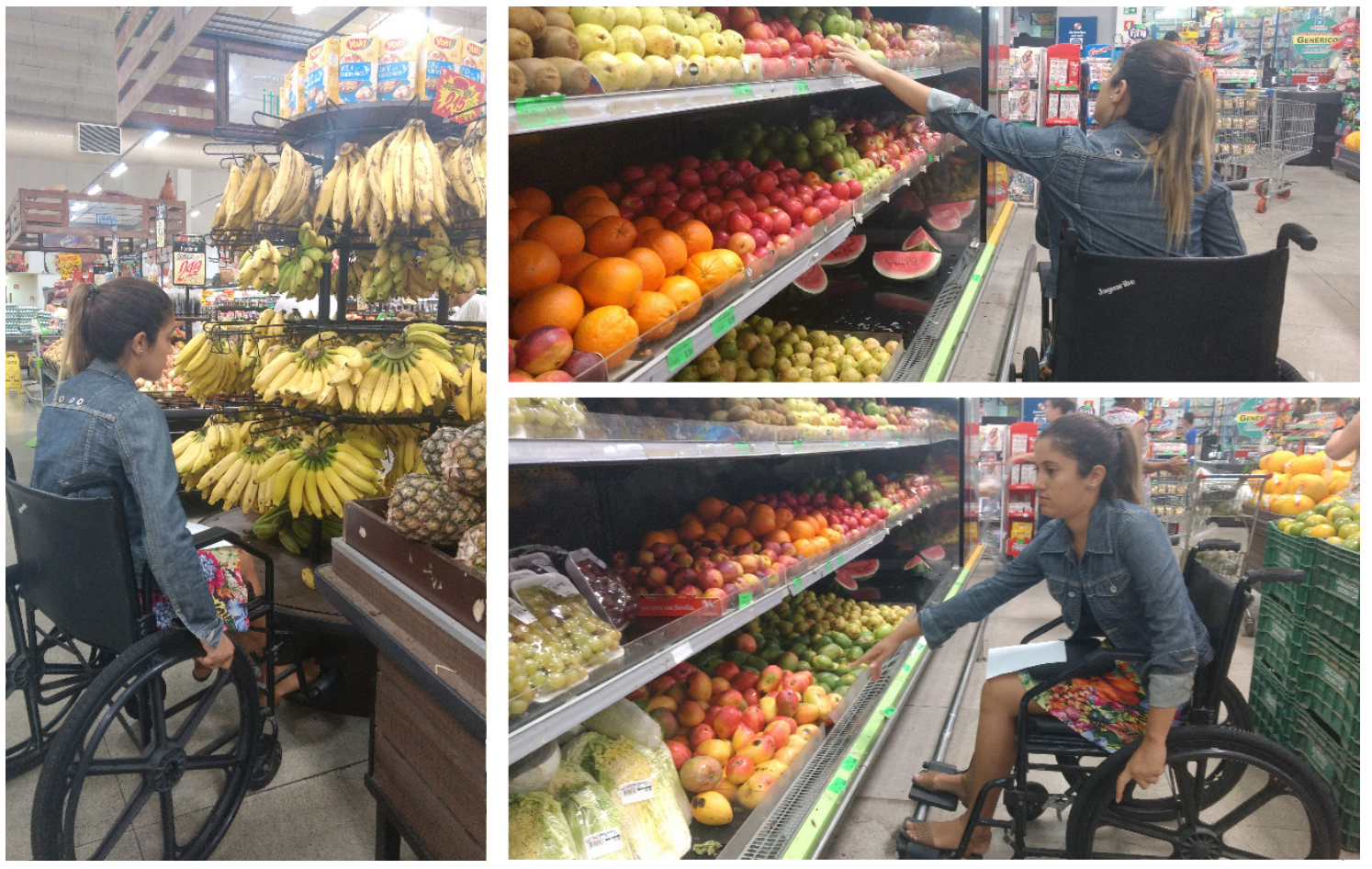

Figuras 7 - Alcances na posição lateral para cadeirantes. Fonte: NBR5090, ABNT, 2004.

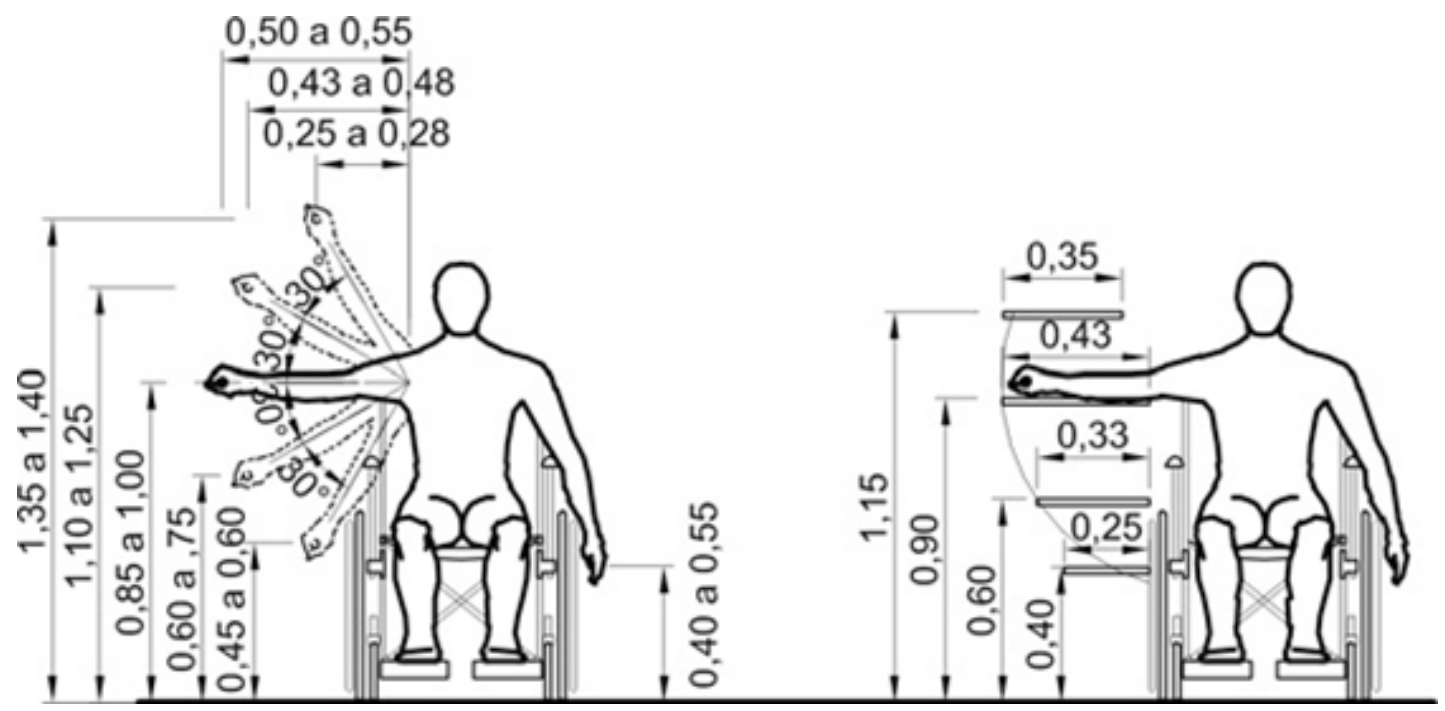

Em relação à Fruteira 2, percebe-se que é bastante eficiente ao usuário sem necessidades físicas, por possuir diversos alcances para a mesma fruta. Para os cadeirantes também é bastante eficiente devido à facilidade de aproximação da cadeira pelo fato da fruteira ter formato cilíndrico. Entretanto, para os usuários com deficiências visuais pode ser perigosa, pois os ganchos que as frutas ficam penduradas podem vir a se enganchar no usuário, por não possuir nenhum sistema de informação que indique o obstáculo. 


\subsubsection{Análise Antropométrica}

Para Boueri (1991), a antropometria é a aplicação dos métodos científicos de medidas físicas nos seres humanos, buscando determinar as diferenças entre indivíduos e grupos sociais, de um modo a adequar os produtos a seus usuários. No projeto de produto é importante ter em mente as diferenças corporais dos vários usuários em potencial. Como se percebeu na análise da tarefa que a maior parte dos problemas estava relacionada aos alcances empregados pelas fruteiras, levou-se em consideração, no estudo antropométrico, os percentis mínimos (5\%) para homens, mulheres, homens idosos, mulheres idosas e cadeirantes (Quadro 2).

Quadro 2: Medidas dos alcances em metros para os percentis 5\%. Fonte: PANERO, 2002, adaptado pelo autor, 2017.

\begin{tabular}{|l|c|c|c|c|c|}
\cline { 2 - 6 } \multicolumn{1}{l|}{} & HOMENS & MULHERES & $\begin{array}{c}\text { HOMENS } \\
\text { IDOSOS }\end{array}$ & $\begin{array}{c}\text { MULHERES } \\
\text { IDOSAS }\end{array}$ & CADEIRANTES \\
\hline Altura média & $163 \mathrm{~cm}$ & $151 \mathrm{~cm}$ & $155 \mathrm{~cm}$ & $140 \mathrm{~cm}$ & $130 \mathrm{~cm}$ \\
\hline $\begin{array}{l}\text { Máximo alcance frontal de } \\
\text { apreensão }\end{array}$ & $80 \mathrm{~cm}$ & $67 \mathrm{~cm}$ & $76 \mathrm{~cm}$ & $64 \mathrm{~cm}$ & $66 \mathrm{~cm}$ \\
\hline $\begin{array}{l}\text { Máximo alcance vertical de } \\
\text { apreensão }\end{array}$ & $210 \mathrm{~cm}$ & $199 \mathrm{~cm}$ & $200 \mathrm{~cm}$ & $182 \mathrm{~cm}$ & $140 \mathrm{~cm}$ \\
\hline
\end{tabular}

Essa decisão se deu pela perspectiva de uma pessoa de percentil médio (50\%) e máximo (95\%) se adequar mais facilmente as alturas das prateleiras, do que um cadeirante, por exemplo. A fim de saber a relação entre as medidas ideias de alcance com as fruteiras analisadas, realizou-se uma medição da altura da primeira prateleira e da última prateleira (ou gancho) e do espaço de fluxo frontal das fruteiras (Quadro 3).

Quadro 3: Medidas das fruteiras quanto aos alcances. Fonte: PANERO, 2002, adaptado pelo autor, 2017.

\begin{tabular}{|l|c|c|c|}
\cline { 2 - 4 } \multicolumn{1}{c|}{} & FRUTEIRA & FRUTEIRA & MEDIDAS \\
\hline Altura da última prateleira/gancho & 1 & 2 & IDEAIS \\
\hline Altura da primeira prateleira/gancho & $160 \mathrm{~cm}$ & $145 \mathrm{~cm}$ & $<120 \mathrm{~cm}$ \\
\hline Espaço de fluxo frontal & $50 \mathrm{~cm}$ & $76 \mathrm{~cm}$ & $>60 \mathrm{~cm}$ \\
\hline
\end{tabular}

Nota-se que a última prateleira fica de difícil acesso para a maioria das mulheres e a primeira prateleira para os homens. Para o problema ser minimizado com êxito, elas devem estar no máximo até a altura dos olhos e no mínimo até a altura dos quadris, a fim de que não haja necessidade de se curvar ou se esticar na hora de escolhê-las.

Com base em PANERO (2002), uma cadeira de rodas tem uma altura de 92,5cm, os braços ficam a 72,5cm do chão e a altura dos olhos fica a aproximadamente $117,6 \mathrm{~cm}$ (Figura 8). Tendo em vista as observações feitas, um cadeirante tem dificuldade em acessar as frutas por conta das alturas incorretas da estrutura das fruteiras que impedem a aproximação frontal, podendo somente ser acessadas lateralmente, o que pode forçar a coluna desse usuário. 
Figuras 8-Medidas ideias para cadeirantes. Fonte: NBR 5090, ABNT, 2004.

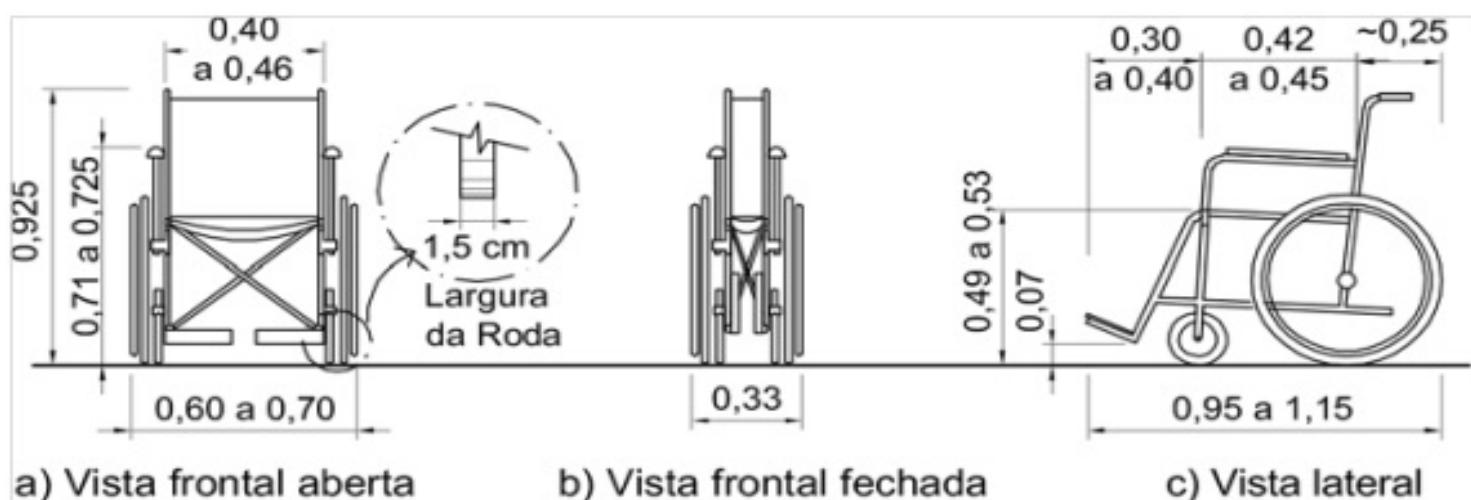

\subsection{Considerações Finais}

Ao final desta pesquisa, observou-se que a aplicação dos conceitos da ergonomia é bastante eficaz na identificação dos problemas vivenciados pelos usuários nas atividades do dia a dia. A realização da análise da tarefa de maneira presencial foi bastante pertinente para perceber de maneira observacional as posturas e pegas e manejos. Foi possível diagnosticar que há uma falta de acessibilidade de maneira geral, tanto no tocante as fruteiras existentes nos supermercados, quanto ao entorno, que poderia quando associado aos mobiliários e ferramentas sensoriais, facilitar as atividades dos consumidores do estabelecimento.

Em relação ao estudo proposto, percebeu-se que para a melhor adequação das fruteiras dos supermercados avaliados em relação ao Design Universal, devem-se melhorar os alcances do produto, onde se vê que a altura ideal para as prateleiras da fruteira está ente 75 a 140 cm, sendo os valores confortáveis de 80 a $120 \mathrm{~cm}$ e os eventuais máximos até $140 \mathrm{~cm}$, e eventuais mínimos de $75 \mathrm{~cm}$ para a prateleira menor. Em relação à altura de alcance dos olhos, as frutas devem estar dispostas na altura máxima de $120 \mathrm{~cm}$, para que o usuário tenha um bom campo de visão para escolher as frutas (Figura 8).

Figuras 9 - Alcances e medidas para cadeirantes. Fonte: NBR 5090, ABNT, 2004.

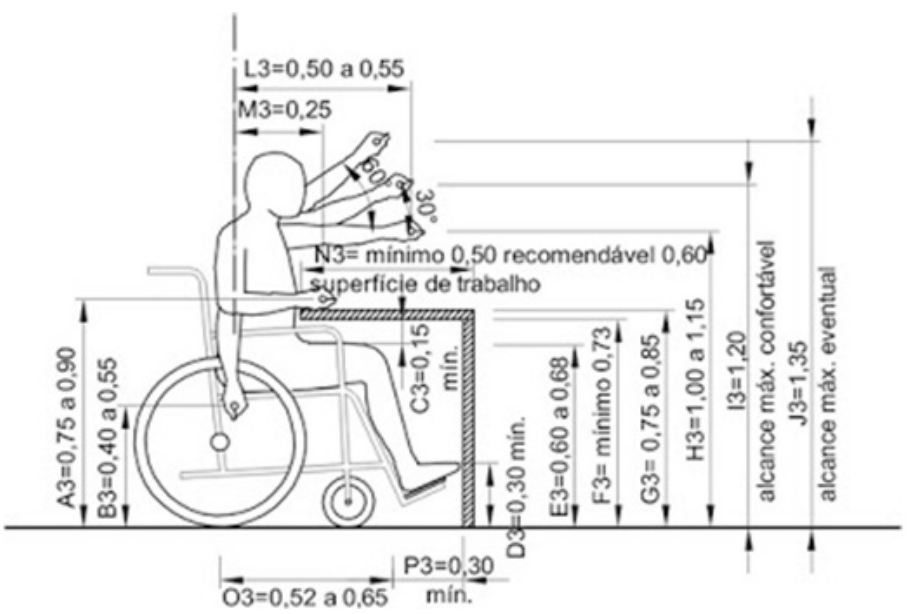

$$
\begin{aligned}
& \text { G3 = Altura das superficies de trabalho ou } \\
& \text { mesas. } \\
& \text { L3 = Comprimento do braço na horizontal, } \\
& \text { do ombro ao centro da mão. } \\
& \text { M3 = Comprimento do antebraço (do } \\
& \text { centro do cotovelo ao centro da mão). } \\
& \text { N3 = Profundidade da superficie de } \\
& \text { trabalho necessária para aproximação }
\end{aligned}
$$

Em relação à sinalização que precifica e informa qual a fruta está sendo exposta, devese procurar fazê-lo também em Braille, a fim de tornar acessível ao público deficiente visual e com números e textos com tamanho maior, para que idosos e pessoas com baixa visibilidade consigam identificar o conteúdo.

Quanto ao espaço no qual a fruteira está inserida, considerando seu entorno, deve-se haver um espaço mínimo de $150 \mathrm{~cm}$ (Figura 9) entre a fruteira e qualquer outro obstáculo, tendo em vista o raio médio de giro de uma cadeira de rodas e o espaço mínimo de 
pessoas em movimento.

Figura 10 - Referências de medidas para rotação da cadeira de rodas. Fonte: NBR 5090, ABNT, 2004.

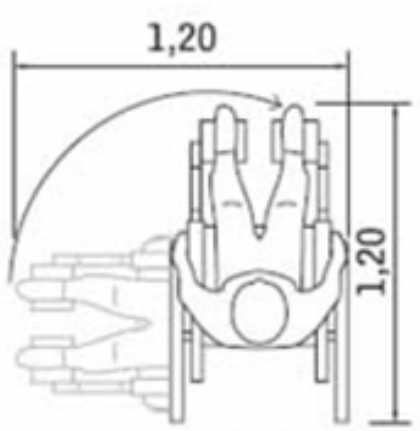

a) Rotaçăo de $90^{\circ}$

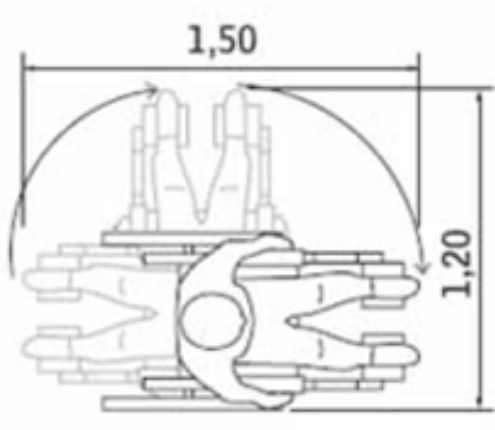

b) Rotação de $180^{\circ}$

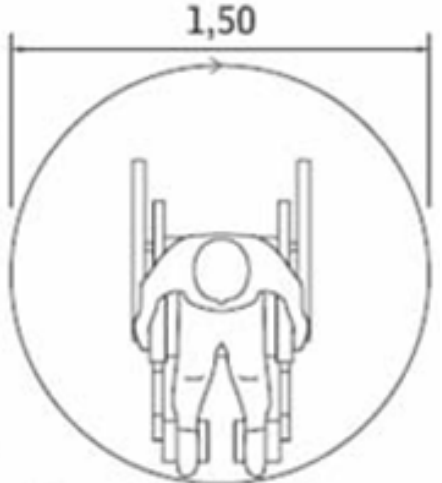

c) Rotação de $360^{\circ}$

Em relação ao alcance para apalpar as frutas e verificar sua qualidade, percebeu-se que a NBR 5090, para cadeirantes, coloca como o alcance máximo frontal com o braço estendido para frente de $50 \mathrm{~cm}$, sendo $40 \mathrm{~cm}$ para atividades sem necessidade de precisão e 25 cm para atividade de longa duração (Figura 10).

Figura 11 - Referências de medidas de alcance frontal para cadeirante. Fonte: NBR 5090, ABNT, 2004.

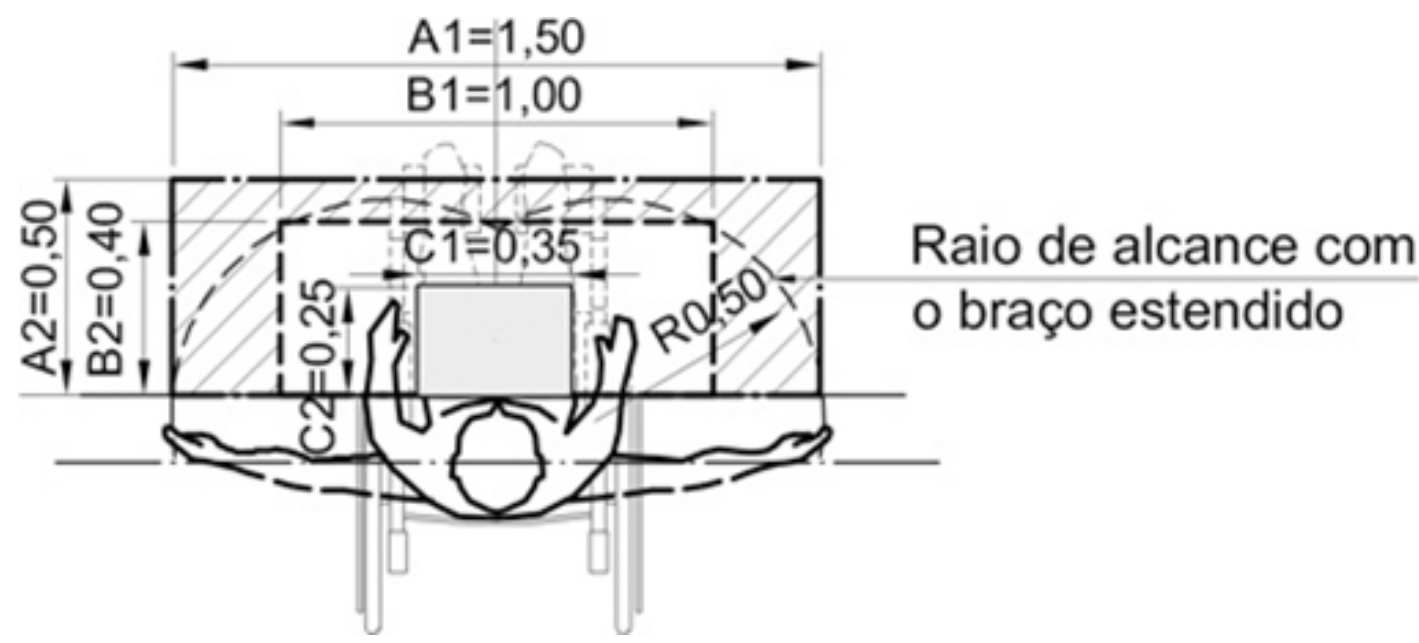

O ideal é que não obtivessem barras de aço que impossibilitam a aproximação com a fruteira pelo cadeirante, pois quando há, a aproximação é comprometida e o usuário necessita pegar as frutas de maneira lateral. Viu-se por fim, que entre a fruteira 1 e a fruteira 2 analisadas nos supermercados, possuem ajustes a serem realizados para atender de maneira satisfatória o maior número de pessoas.

Outras estratégias poderiam ser utilizadas como colocar a mesma fruta em diferentes alcances a fim de minimizar essa dificuldade, mas essa opção pode comprometer a logística do estabelecimento e diminuir a quantidade de espaço para disposição das frutas. 0 ideal é que o design absorva mais as ferramentas da ergonomia de maneira mais aprofundada, de modo a não utilizar apenas as medidas médias para os produtos desenvolvidos, comprometendo desse modo a acessibilidade.

\section{REFERÊNCIAS}

ASSOCIAÇÃO BRASILEIRA DE NORMAS TÉCNICAS. NBR 5090: Acessibilidade a edificações, mobiliário, espaços e equipamentos urbanos. Rio de Janeiro, p. 6, 8, 10 e 11, 2004. 
ABERGO. A certificação do ergonomista brasileiro. Editorial do Boletim 1/2000, Associação Brasileira de Ergonomia, 2000.

ADUL, Jan et. al. Ergonomia prática. São Paulo: Edgar Blücher, 2004.

BAXTER, M. Projeto de produto. São Paulo: Edgard Blücher, 1998.

BIFANO et. al. A análise ergonômica da atividade como ferramenta de auxílio ao QFD no processo de desenvolvimento de produtos. Congresso Brasileira de Gestão e Desenvolvimento de Produto, 2000.

BONSIEPE, Gui et. al. Metodologia experimental: desenho industrial. Brasília: CNPq/ Coordenação editorial, 1984.

BOUERI FILHO, J. Antropometria Aplicada à Arquitetura. São Paulo: FAU-USP, 1991.

CARLETTO et. al. Desenho Universal: um conceito para todos. São Paulo, 2008.

GOMES FILHO, João. Ergonomia do Objeto: Sistemas de Leitura Ergonômica. São Paulo: Escrituras editora, 2003.

GUTIERREZ, A. Danos mecânicos pós-colheita em pêssego fresco. 124 f. Tese (Doutorado). Piracicaba. Universidade de São Paulo, 2005.

IIDA, I. Ergonomia: projeto e produção. 2a ed. São Paulo: Edgar Blücher; 2005.

LIU, R. Health benefits of fruits: implications for disease prevention and health promotion. 19 f. Cabo Frio, 2006. v.1, p.36-44.

PANERO, J et. al. Dimensionamento Humano para espaços e Interiores. México: GG, 2002.

RIBEIRO, L. $\mathbf{O}$ design universal como abordagem ergonômica na concepção de produtos. 8 f. Santa Catarina , 2001.

SUDHEER et. al. Maturity and harvesting of fruits and vegetables. New Deli: New India, 2007. cap 3, p.31-45.

TRANI, E. Desenho Universal: habitação de interesse social. São Paulo. Governo do Estado, 2010.

VIDAL, M.C. Ergonomia na empresa: útil, prática e aplicada. Rio de Janeiro: Editora Virtual Científica, 2002.

Sobre as autoras:

Thays da Costa Oliveira (graduanda), UFAL <tthaysdacosta国gmail.com>

Débora Clarissa Ferreira de Pontes (graduanda), UFAL <deboracfpontes国gmail.com>

Maria Eduarda Ramos Cavalcanti Rosa (mestre), UFAL < dudah.cavalcanti@gmail.com> 